\title{
O ABORTO, UMA CONDIÇÃO PARA A EMANCIPAÇÃO FEMININA
}

\author{
MICHÈLE FERRAND
}

Universidade Paris 8

\begin{abstract}
Resumo: Na França, o atraso com relação a outros países ocidentais sobre a liberalização do controle de nascimentos se explica pela existência de um natalismo de Estado. A contracepção foi autorizada somente em 1967, com muitas restrições. Os eventos de maio de 68 e, sobretudo, a ascenção do feminismo conseguiram impor uma liberalização maior, que permitiu às mulheres, em 1975, o direito de solicitar um aborto nas primeiras dez semanas de gravidez. A autora, socióloga, participou ativamente do movimento de mulheres. Paralelamente, ela escolheu o aborto como tema de pesquisa. É sua trajetória, por meio das diferentes etapas da liberação, mas também os problemas sociológicos e políticos que ela pôde identificar objeto deste artigo, assim como a apresentação dos principais resultados de pesquisa.
\end{abstract}

Palavras-chave: feminismo; aborto; contracepção; direitos reprodutivos.

Na França, a legislação sobre o controle da procriação é historicamente marcada pelo natalismo do Estado. Esse natalismo foi concretizado no que as francesas chamaram de "lei celerada" de 1920, lei que interditava todos os meios de limitar os nascimentos (com exceção do preservativo para se proteger da sífilis), quer se tratassem de práticas preventivas (contracepção) ou de práticas abortivas.

Ao mesmo tempo que se difundiam no Norte da Europa e da América técnicas que permitiam evitar uma gravidez, as francesas não tinham outra solução para evitar um nascimento do que a de recorrer ao aborto clandestino, apesar do perigo e do risco de condenação penal. Para as mais pobres, os abortos se faziam em condições de higiene terríveis, graças às aborteiras pouco qualificadas chamadas de "fazedoras de anjos". As mulheres mais abastadas podiam ir abortar no exterior (primeiro na Suíça e logo em seguida na Grã-Bretanha) ou pagar muito caro a um médico francês que aceitasse exercer essa prática na ilegalidade.

Essa injustiça social e suas conseqüências para a saúde pública (numerosas mulheres morriam em função de um aborto mal executado) estiveram na origem, nos anos 60, de um conjunto de argumentos em favor da difusão da contracepção moderna (pílula e DIU, acessíveis nos países anglo-saxões) como meios de lutar contra o aborto. A direita modernista, sob a pressão de suas frações mais progressistas e notadamente dos franco- 
maçons, começava a admitir o direito dos casais de decidir o número de seus filhos. Em função disso, apesar da oposição da Igreja Católica, da direita natalista e do corpo médico, o deputado gaulliste' Lucien Neuwirth consegue fazer votar, em 1967, uma lei moderna autorizando a difusão da contracepção sob controle médico. Porém, os atrasos na publicação dos decretos de sua aplicação, assim como seu caráter restritivo (prescrição médica obrigatória, interdição às mulheres solteiras menores ${ }^{2}$ sem autorização parental, não reembolso pelo sistema público de saúde), além das reivindicações libertárias do movimento de maio de 68, mostraram muito rapidamente os limites dessa lei.

O feminismo francês, que reapareceu em 1970, imediatamente se apropriou da reivindicação da livre escolha da procriação pelas mulheres. O slogan "aborto e contracepção, livres e gratuitos para todas" foi um dos catalisadores mais eficazes do movimento nascente. Todas as mulheres se sentiam implicadas. Como em muitos outros países, as lutas das mulheres tomaram novas formas e adotaram táticas específicas.

Muitos acontecimentos marcaram o longo caminho que iria culminar com a descriminalização do aborto. Um dos mais originais foi, sem dúvida, o "Manifeste de 343 sans-salopes", ${ }^{3}$ publicado por um periódico de esquerda, o Nouvel Observateur. ${ }^{4}$ Esse manifesto proclamava "Eu declaro ter abortado" e estava assinado por numerosas anônimas, mas sobretudo por mulheres conhecidas, como Simone de Beauvoir, Catherine Deneuve e muitas outras, que, por sua notoriedade, acreditava-se que não seriam processadas. Elas realmente não o foram. Manifestações gigantescas tiveram lugar ao menos uma ou duas vezes por ano durante muitos anos. Para ser mais eficaz, o Movimento de Liberação das Mulheres (MLF) se associou com o Movimento pela Liberalização do Aborto e da Contracepção (MLAC) ${ }^{5}$ para praticar abortos, no início, clandestinos, mas logo públicos, efetuados por aspiração, uma nova técnica até então desconhecida na França. A lei era abertamente descumprida ou, ao menos, não aplicada. Pouco a pouco, como mostravam as pesquisas, a opinião pública tornava-se cada vez mais favorável à idéia de uma liberalização.

Depois de longas lutas, dois projetos de lei, uma mudança de presidente, um debate tumultuado no parlamento, a ministra da Saúde, Simone Veil, conseguiu fazer votar a lei de 1975. As mulheres "cujo estado de gravidez as colocasse em situação de miséria, angústia ou perigo" estavam autorizadas a recorrer à Interrupção Voluntária da Gravidez (IVG), respeitadas certas exigências: tempo de gravidez (menos de 10 semanas), condições de realização (num hospital autorizado e por um médico) e entrevista obrigatória explicitando a demanda a uma conselheira "psicóloga". As mulheres viam, portanto, o reconhecimento do direito de decidir, mas "sob controle", pois a aposta natalista estava ainda presente e sua emancipação ainda era percebida como "perigosa" para a ordem social.

Eu participei do movimento de mulheres desde que conheci sua existência, enquanto era ainda estudante (mas já casada e mãe de uma filha, na verdade não planejada, pois, como menor, eu não conseguia obter a pílula). Desde o início me engajei nessa luta pela liberdade de procriar, tentando fazer coincidirem minhas opções políticas e meus estudos. Assim, propus como trabalho de DES $^{6}$ uma pesquisa sobre o custo econômico e social do

\footnotetext{
' Partidário de Charles de Gaulle.

${ }^{2}$ A maioridade legal era então aos 21 anos!

${ }^{3}$ Manifesto das 343 sem-vergonha (nota da tradutora).

${ }^{4}$ O mesmo que, aliás, infelizmente, achou inteligente publicar uma foto de Simone de Beauvoir nua na capa pelo centésimo aniversário de seu nascimento!

${ }^{5}$ Movimento pela Liberalização do Aborto e da Contracepção, grupo misto, compreendendo numerosos médicos homens (nota da tradutora).

${ }^{\circ}$ Curso de pós-graduação equivalente ao mestrado no Brasil.
} 
aborto clandestino, trabalho extremamente difícil de realizar, pois as informações sobre esse objeto eram muito difíceis de encontrar em 1972, no momento em que se começava a vislumbrar uma modificação da lei. A escolha desse objeto de pesquisa preocupou um pouco os professores que me cercavam, mas eles me deixaram fazer o trabalho.

Uma vez diplomada, eu entrei no CNRS $^{7}$ como pesquisadora e então pude continuar a trabalhar livremente nesse tema, favorecida pelos financiamentos públicos, pois a interrogação sobre os efeitos da lei era muito forte. Graças à associação da contracepção reembolsada pelo Estado com o aborto autorizado, num contexto em que o feminismo denunciava a "maternidade escrava", ${ }^{8}$ as francesas iriam parar de fazer filhos? O que nos interessava mais - eu trabalhava em colaboração com outra pesquisadora, Anne Marie Devreux - era o controle social sobre as mulheres e o surgimento, nessa direção, de novas normas e injunções concernentes à sexualidade e à maternidade, o que nós chamamos na época de "normalização contraceptiva". Essa noção mostrava que o poder concedido às mulheres era pago por elas por meio de uma forte medicalização normativa sobre tudo o que dizia respeito a seus corpos.

De pesquisa em pesquisa, finalmente publiquei, em 1987, com a demógrafa feminista Maryse Jaspard, a primeira obra de referência sobre a interrupção voluntária da gravidez na França. Nesta época, a IVG não era mais um problema social: a lei era mais ou menos aplicada e a vigilância demográfica havia dado certa segurança aos políticos: ela mostrava que o número de abortos não havia explodido; que cerca de uma mulher, em cada três, possivelmente faria um aborto em sua vida; e que o número de filhos continuava em torno de dois por mulher. Assim, durante as duas décadas seguintes à confirmação da lei em 1979, ${ }^{9}$ todas as intervenções legislativas foram para melhorar as conquistas da lei. $O$ reembolso foi votado em $1982,{ }^{10}$ quando a esquerda chegou ao poder, fortalecendo a luta contra os movimentos "pró-vida" que tentavam impedir os centros de IVG de funcionar. Surgiu também a possibilidade do aborto medicamentoso, por meio da RU 486, ${ }^{1}$ ou seja, apesar de alguns oponentes, sempre virulentos, e por vezes dos problemas de prazos e de acesso aos serviços, não parecia que existissem maiores dificuldades para as mulheres que desejassem recorrer ao IVG.

Sem dúvida, por essas razões eu me consagrei, no fim dos anos 80 , a outros temas de pesquisa, sempre relacionados com minhas perspectivas feministas: a paternidade, a articulação entre trabalho doméstico e trabalho profissional, o desempenho das meninas na escola etc.

Porém, restava, a meus olhos, uma interrogação: o lugar e a importância do aborto na vida das mulheres. O que me parecia particularmente paradoxal era a grande estabilidade do número de abortos. Mesmo com a larga difusão da contracepção, que deveria ter reduzido seu número a partir dos anos 70, o número de abortos passava sempre de 200 mil por ano (por 700 a 800 mil nascimentos).

\footnotetext{
${ }^{7}$ Conselho Nacional de Pesquisa Científica, da França (nota da tradutora).

${ }^{8}$ Título de uma obra publicada coletivamente pelas mulheres do MLF.

9 Uma especificidade muito particular da lei de 1975 era seu caráter provisório: ela foi votada apenas por cinco anos para que se pudesse medir seus efeitos, notadamente demográficos.

${ }^{10} \mathrm{Na}$ ocasião de seu retorno ao poder, em 1986, Jacques Chirac tentou voltar atrás sobre o princípio do reembolso, o que levou imediatamente a grandes manifestações públicas. Ele desiste! Na França os medicamentos indicados por médicos são reembolsados ao segurado pelo sistema público de saúde em $60 \%$ de seu custo (nota da tradutora).

${ }^{11}$ Mifepristona, a chamada pílula abortiva (nota da tradutora).
} 
Foi neste momento que, no fim dos anos 90 , uma jovem pesquisadora, Nathalie Bajos, propôs voltar a trabalhar nesse objeto, no quadro de uma grande enquete impulsionada pelo INED ${ }^{12}$ e pelo INSERM. ${ }^{13}$ Aceitei imediatamente, curiosa para saber 0 que havia mudado. Essa pesquisa era ainda mais interessante visto ter como objetivo concreto propor eventuais modificações para a lei.

A pesquisa foi realizada em dois momentos. Primeiramente, em 1999 e 2000, foi feita uma pesquisa qualitativa (GINE) por meio de entrevistas biográficas com 80 mulheres que haviam tido uma gravidez não planejada nos últimos cinco anos. Em seguida, de 2002 a 2005, realizou-se uma pesquisa quantitativa, com aplicação de questionário interrogando sete mil mulheres por telefone sobre seu itinerário contraceptivo e procriativo. Nesta parte da pesquisa, foram particularmente estudadas as falhas da contracepção e os recursos à IVG. O questionário foi pensado como complementar à problemática e aos primeiros resultados da enquete por entrevista.

Três níveis de análise foram levantados pelos dois caminhos de pesquisa: o do acesso à contracepção e às falhas contraceptivas em primeiro lugar, o do processo de decisão diante de uma gravidez não prevista em seguida e, por fim, numa perspectiva centrada nos problemas de saúde pública, o das desigualdades eventuais de acesso aos cuidados, nos casos de demanda de IVG.

O que mostra essa dupla pesquisa é que, em primeiro lugar, confirma-se a percepção de que a liberalização do aborto não teve conseqüências fatais para a natalidade. A França se caracteriza, na Europa, pela taxa de fecundidade mais elevada, depois da Irlanda (onde o aborto é estritamente proibido), embora a proporção de mulheres sem filhos continue estável: $10,1 \%$ para a geração de 1940 e 10,8\% para a geração $1960 .{ }^{14} \mathrm{~A}$ maternidade continua majoritariamente pensada e vivida no quadro da conjugalidade: a porcentagem de nascimentos naturais, nos quais o filho não é reconhecido pelo pai, continua estável a partir dos anos setenta e é muito pequena, menos de $10 \%$. Não diferente do que antigamente, as mulheres não querem ter filhos sozinhas, elas pensam prioritariamente no quadro de um casal de pais. Mais ainda, o aborto não se banalizou, ele não substituiu a contracepção, e as mulheres continuam a considerá-lo como um "último recurso".

Por outro lado, esta pesquisa mostrou a dificuldade de praticar uma contracepção cotidianamente ao longo de toda a vida. Afora a má prescrição ou os medos dos efeitos secundários, é também a relação afetiva que está em questão. Nossos resultados permitem compreender como a gestão do "risco" na utilização de um certo método de contracepção pode ser muito diferente do simples risco de gravidez. Sua análise permite colocar em evidência o funcionamento da dominação masculina, que pode se manifestar em todas as etapas da vida em comum, que vão do ato sexual à gravidez, etapas que são freqüentemente negociadas pelo casal em benefício do homem, priorizando seu desejo, quer se trate da utilização da contracepção na primeira relação, da escolha de uma contracepção supervisionada por médico, do respeito às restrições contraceptivas e, enfim, da decisão de abortar ou não. Essa dominação masculina se revela essencialmente por meio das expectativas assimétricas dos homens e das mulheres. A perspectiva de uma gravidez (e, portanto, a necessidade ou não de se proteger) aparece, assim, como um jogo da relação e também de suas modalidades pela importância da primazia dada pelas mulheres ao prazer masculino.

\footnotetext{
12 Instituto Nacional de Estudos Demográficos.

${ }^{13}$ Instituto Nacional de Saúde e Pesquisa Médica.

${ }^{14}$ France PRIOUX, 2004/2005.
} 
A problemática elaborada e colocada à prova nessas duas pesquisas foi em seguida reformulada para ser adaptada a outros contextos, notadamente aqueles das sociedades do Sul. É assim que desenvolvo atualmente, sempre com Nathalie Bajos, uma pesquisa sobre a pílula do dia seguinte em quatro países da África "Burkina Faso, Gana, Marrocos e Senegal " interrogando mulheres, mas também homens e prestadores de serviços médicos, nas capitais desses países. Uma primeira publicação está prevista para 2009.

\section{Conclusão}

A liberalização do aborto, que seguiu a da contracepção, foi primeiramente apresentada como o direito dos pais de terem os filhos que desejassem e somente esses e contribuiu sobretudo para redefinir a identidade feminina, permitindo a passagem de um modelo do "destino maternal" a um modelo muito mais diversificado, embora este exigisse ainda três componentes: a maternidade, a realização sexual e o investimento profissional.

Liberando em grande medida as mulheres do espectro da gravidez não desejada e permitindo uma dissociação total entre o ato sexual e a procriação, a contracepção e a possibilidade de aborto no caso de os métodos contraceptivos não funcionarem colocam as mulheres, teoricamente, em uma posição equivalente à dos homens diante dos riscos das relações sexuais. Isto se traduz pelo aumento muito claro da satisfação das mulheres em sua vida sexual, como mostra a última pesquisa francesa sobre a sexualidade..$^{15}$

A liberdade de procriação permitiu uma verdadeira abertura do mundo social e profissional para as mulheres. Se sempre houve na França uma grande tradição do trabalho das mulheres, a modificação essencial se manifestou na construção de trajetórias profissionais, quando não mais se precisava parar para criar os filhos, o que ocorria com as mães em gerações precedentes. A taxa de atividade feminina de mães de duas crianças passa de $26 \%$ em 1962 a $76 \%$ em 2002. A difusão da contracepção feminina e, sobretudo, a possibilidade de recorrer ao aborto em caso de gravidez não prevista inegavelmente participaram dessa mutação da relação das mães com a atividade profissional, o que Ihes permitiu pensar numa carreira de atividades contínuas.

Na escolha de abortar, o contexto relacional - a duração da relação, sua institucionalização, a existência de filhos do casal - mas também os capitais que a mulher detém e sua independência material são determinantes. No que concerne à decisão, é principalmente a capacidade do homem (e seu próprio desejo) de formar com a mulher um casal de pais que intervém. A IVG aparece como solução quando não há pai (relação efêmera ou com pouco investimento), quando não há ainda pai (relação iniciante em que a prioridade dada à relação amorosa leva a um risco para o futuro do casal no caso de um filho) ou quando é possível que não haja mais pai (quando o casal vai muito mal). E a IVG pode ser então escolhida, mesmo que a mulher esteja consciente de um verdadeiro desejo de ter filhos ou de uma urgência temporária, quando ela passou dos quarenta anos e poderia ter os meios de suprir a criação de um filho potencial.

Enfim, diante da dificuldade de praticar uma contracepção sem falhas ao longo de toda a sua vida fértil, o aborto aparece como totalmente necessário às mulheres, é verdadeiramente reconhecido o direito de serem mais do que "geradoras". Uma mulher entre duas na França, e sem dúvida podemos pensar que não é tão diferente em outras sociedades, será confrontada, mesmo utilizando métodos anticoncepcionais, com uma gravidez não desejada ou não realizável. Sem a possibilidade de recorrer ao aborto em caso de falha, a contracepção não representa assim mais que uma revolução inacabada.

\footnotetext{
${ }^{15}$ Nathalie BAJOS, Michel BOZON e Nathalie BELTZER, 2008. Enquete da qual eu participei.
} 


\section{Referências bibliográficas}

BAJOS, Nathalie; BOZON, Michel; BELTZER, Nathalie. L'enquête sur la sexualité en France. Paris: La découverte, 2008.

PRIOUX, France. "L'évolution démographique récente en France". Population, Paris, v. 60, p. 443-487, 2004/2005.

\section{Principais publicações da autora sobre o tema}

BAJOS, Nathalie; FERRAND, Michelle et équipe GINE. De contraception à l'avortement, sociologie des grossesses non prévues. Paris: Editions INSERM, 2002. 345 p. Préface de L. Neuwirth. (Collection Santé Publique).

FERRAND, Michelle; JASPARD, Maryse. L'interruption volontaire de grossesse. Paris: PUF, 1987. (Collection Que sais-je).

FERRAND, Michelle. Féminin, masculin. Paris: Editions La découverte, 2004.

\section{Artigos de Michèle Ferrand, individuais ou em colaboração}

"L'appel au désir d'enfant dans le discours et la pratique des médecins". Les Temps Modernes, n. 426, p. 1.284-1.297, janv. 1982.

"Médicalisation et contrôle social de l'avortement: derrière la loi, les enjeux". Revue Française de Sociologie, v. XXII, n. 3, p. 383-396, 1982.

"La loi sur l'avortement. Chronologie des événements et des prises de positions". Revue Française de Sociologie, v. XXII, n. 3, p. 503-518, 1982. (en collaboration avec A.-M. Devreux).

"Les bénéfices (concrets et symboliques) de la médicalisation de la procréation". In: VILAINE, A.-M. de et al. (Eds.). Maternité en mouvement. PUG/Editions Saint Martin, 1986. p. 171175.

"Les médecins face à l'avortement". Sociologie du Travail, n. 2, p. 367-379, 1989.

"Face à la question de l'avortement: l'aller et retour entre militantisme et démarche scientifique". Les Sociologues et les Pratiques Biomédicales= Sociologists and Biomedical Practices. Le Sociologue Dans le Débat en Europe, IRESCO CNRS, p. 78-89, 1991. Table ronde n. 4.

"Os direitos reprodutivos na França". Revista Estudos Feministas, Rio de Janeiro, p. 225-247, 1994. Colloque de Recherche Brésil-France-Québec.

"Analysis of the Underestimation of Induced Abortions in a Survey of the General Population in France". European Journal of Contraception and Reproductive Health Care, v. 5, p. 52-60, 2000. (en collaboration avec S. Houzard, N. Bajos, J. Warszawski, C. de GuibertLantoine, M. Kaminski, H. Leridon, N. Lelong, B. Ducot et D. Hassoun).

"L'avortement à l'âge de raison". Mouvements, n. 17, p. 99-105, 2001. (en collaboration avec Nathalie Bajos).

“Filières d'accès à l'IVG en France: apports conjoints d'une approche qualitative et d'une approche quantitative". Revue Française d'épidémiologie et de Santé Publique, n. 6, 2003. (avec Nathalie Bajos, Caroline Moreau, Jean Bouyer, équipe GINE et équipe COCON).

"La contraception: levier réel ou symbolique de la domination masculine?". Sciences Sociales et Santé, v. 22, n. 3, p. 117-140, 2004. (en collaboration avec Nathalie Bajos). 
"Pourquoi le nombre d'avortement n'a-t-il pas baissé en France depuis 30 ans?". Population et Sociétés, n. 407, déc. 2004. 4 p. (en collaboration avec N. Bajos, C. Moreau et H. Leridon).

"L'Etat, les lois du sexe et le genre". In: MOSSUZ-LAVAU (Dir.). Genre et politiques. Editions La Martinière, mars 2004. p. 300-323.

"L'avortement et la contraception". In: MARUANI (Dir.). Femmes, genre et sociétés, L'état des savoirs. La découverte, mars 2005. p. 114-122. (en collaboration avec N. Bajos).

"La liberté de procréation, une révolution inachevée?". Sciences Humaines, France 2005, Portrait d'une Société, p. 56-60, 2005. (Hors-Série 50).

"La contraception a permis aux femmes de mettre en place un calendrier des naissances". Le Monde, 3 juil. 2005.

"L'interruption volontaire de grossesse et la recomposition de la norme procréative". Sociétés Contemporaines, n. 61, p. 91-117, 2006. (en collaboration avec N. Bajos).

"L'avortement ici et ailleurs". Sociétés Contemporaines, n. 61, p. 2-18, 2006. (en collaboration avec N. Bajos).

[Recebido em maio de 2008

e aceito para publicação em junho de 2008]

Tradução de Cristina Scheibe Wolff

\begin{abstract}
Abortion, a Condition for Gender Emancipation
Abstract: Falling behind other western countries concerning the liberalization of birth control in France is explained by a natalism of State. The contraception was authorized only in 1967, under many restrictions. The May 1968 events and mainly the rising of feminism could impose an even higher liberalization, which allowed women, in 1975, to require abortion in the first ten weeks of pregnancy. The author of this article, a sociologist, participated actively in the women's movement. Al the same time, she has chosen abortion as research subject. It is not only her trajectory, through the different liberation stages, but also the sociological and political problems she could identify, that are the main issues in this article, as well as the introduction of the main research results.

Key Words: Feminism; Abortion; Contraception; Reproductive Rights.
\end{abstract}

